\title{
Recent advances in Japanese encephalitis
}

\author{
Tom Solomon
}

Departments of Neurological Science and Medical Microbiology, University of Liverpool, Liverpool, United Kingdom; and WHO Center for Tropical Diseases, University of Texas Medical Branch, Galveston, Texas, USA

Japanese encephalitis (JE), the most important cause of epidemic encephalitis worldwide, is confined to Asia, but its geographical area is spreading. West Nile virus, and other closely related flaviviruses, cause similar disease elsewhere. Recent cryoelectron microscopic studies have characterized the flavivirus envelope protein as a new class of viral fusion protein (class II), and examined its arrangement on the virion surface. Changes in the envelope protein's hinge region, or its putative receptor-binding domain, are associated with changes in neurovirulence in animal models of JE. Clinically, JE causes a wide range of presentations, including a poliolike flaccid paralysis. Seizures and raised intracranial pressure are associated with a poor outcome, and may be potentially treatable. A safe efficacious formalin-inactivated vaccine against JE has been available for many years, but is too expensive for use in most Asian countries. A newer live attenuated vaccine has been used in China, but its use elsewhere has been restricted by regulatory concerns. A chimeric vaccine in which JE structural proteins are inserted into the 17D yellow fever vaccine backbone is one of several vaccines in development. There are no established antiviral treatments against JE. Interferon alpha was the most promising drug in small open trials, but a recent double-blind placebo controlled trial showed that it did not affect the outcome in children with JE. Journal of NeuroVirology (2003) 9, 274-283.

Keywords: arthopod-borne virus; CNS infection; flavivirus; vaccine; West Nile virus

\section{Introduction}

Although considered by many in the West to be a rare and exotic disease, Japanese encephalitis (JE) is the most important causes of epidemic encephalitis worldwide, causing an estimated 35,000 to 50,000 cases and 10,000 to 15,000 deaths annually (Tsai, 2000). Outbreaks of encephalitis were described in Japan from the 1870s onwards. The virus was first isolated in 1935, and has been recognized across Asia since then (Figure 1) (Solomon, 2000). JE virus (JEV) is a member of the genus Flavivirus (family Flaviviridae) that is transmitted naturally in an

Address correspondence to Dr. Tom Solomon, Department of Neurological Science, University of Liverpool, Walton Centre for Neurology and Neurosurgery, Liverpool L9 7LJ, United Kingdom. E-mail: tsolomon@liv.ac.uk

The author thanks Dr. Alan Barrett for helpful discussions. Some of the work described in this review was funded by the Wellcome Trust of Great Britain.

Received 7 November 2002; accepted 13 November 2002. enzootic cycle among birds, pigs, and other vertebrate hosts by mosquitoes-especially Culex tritaeniorhynchus. Humans become infected when they encroach upon this enzootic cycle. Closely related mosquito-borne flaviviruses in the JE serogroup cause neurological disease elsewhere across the globe, including St Louis encephalitis virus, Murray Valley encephalitis virus, and West Nile virus. The Flavivirus genus also includes yellow fever and dengue, which cause hemorrhagic fevers and feverarthralgia-rash syndromes, and only occasionally central nervous system (CNS) disease (Solomon et al, 2000b), the tick-borne encephalitis viruses, and viruses with no known vector that are not important human pathogens (Figure 2). In recent years, the application of molecular biological approaches have helped elucidate the structure of flaviviruses, giving insights into viral pathogenesis and vaccine development. Detailed clinical studies have allowed a better understanding of the pathophysiology, and the first trial of an antiviral drug has been reported. 


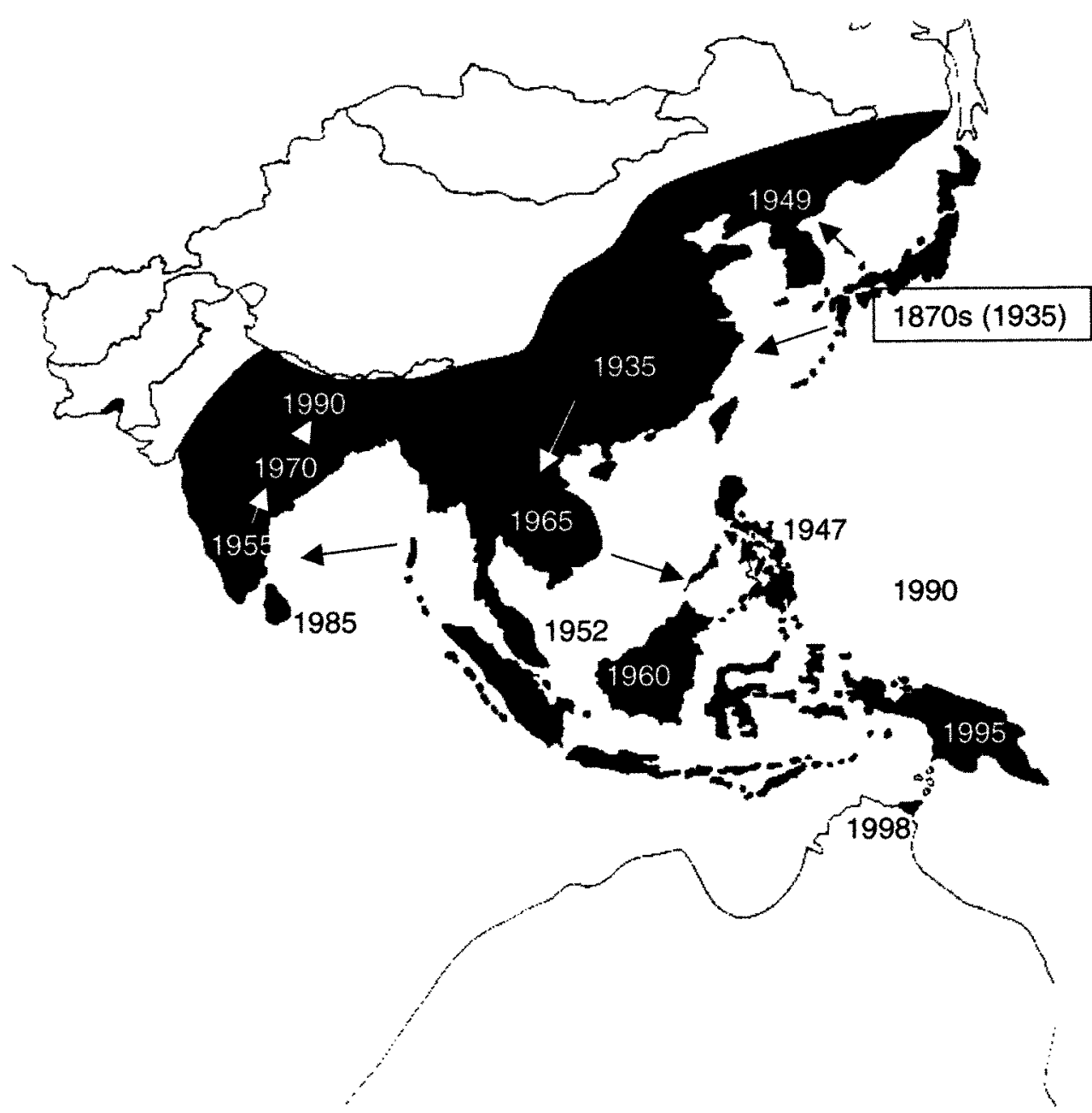

Figure 1 Current distribution of Japanese encephalitis. The approximate dates of the first major outbreaks, or first virus isolations, are shown. Modified from Solomon, 2000, with permission.

\section{Viral replication and morphogenesis}

Like the other flaviviruses, the JEV virion consists of a single strand of positive-sense RNA, wrapped in a nucleocapsid and surrounded by a glycoproteincontaining envelope. The RNA comprises a short $5^{\prime}$ untranslated region (UTR), a longer $3^{\prime}$ UTR, and a between them a single open reading frame (Chambers et al, 1990). This codes for a single polyprotein which is co- and post-translational cleaved by viral and host proteases into three structural proteins (core-C; pre-membrane-PrM; and envelope-E), and seven nonstructural (NS) proteins (NS1, NS2A, NS2B, NS3, NS4A, NS4B, NS5). The C protein is highly basic and combines with the RNA to form the nucleocapsid. The PrM is closely associated with the E protein, forming a heterodimer, and is thought to act as a 'chaperone' to it, impairing its function until after virion release. Immediately prior to virion release, the PrM protein is cleaved by a furin-like protease to its mature M protein form. This allows the formation of E protein homodimers, which are thus 'activated' (Stadler et al, 1997). The E protein is the largest structural protein, consisting of nearly 500 amino acids with up two potential gylcosylation sites. It is the major target for the humoral immune response, and is thought to be important in viral entry into host cells. Studies with monoclonal antibodies in the late 1980s suggested three antigenic domains (Roehrig et al, 1989), and these were confirmed more recently when the three dimensional structure of the ectodomain of the flavivirus tick-borne encephalitis virus was determined by x-ray crystallography (Rey et al, 1995). Domain III is the putative receptor binding domain (by which virions attach to the yet-to-be-identified host cell receptor), domain II is the dimerization domain, and domain I has a central $\beta$ barrel and is the hinge domain that links the other two domains. Following viral attachment to the cell surface, flaviviruses enter cells by endocytosis, and subsequent fusion of the virus' lipid membrane, with the endosome membrane allows viral RNA to penetrate into 


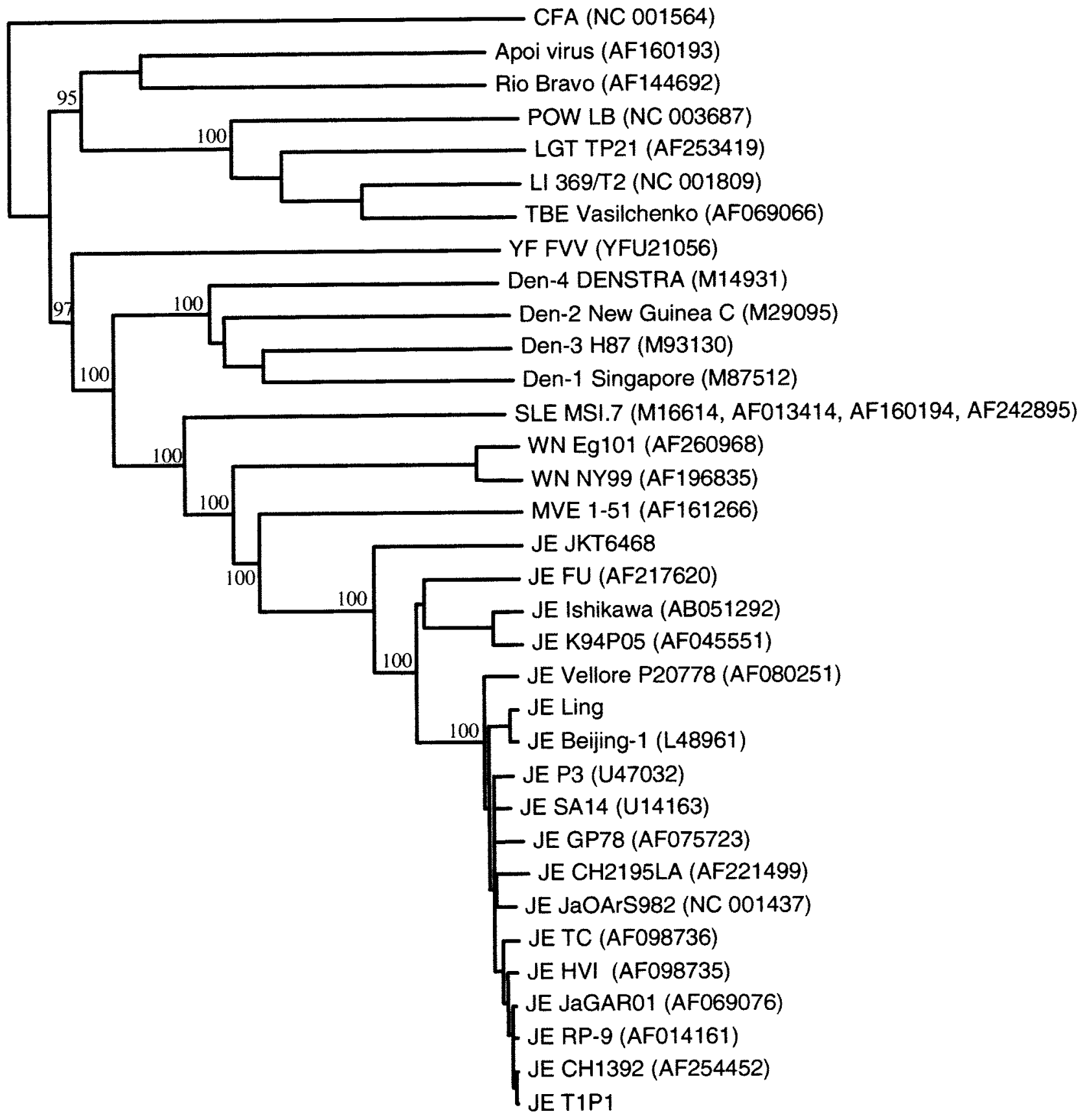

500 changes

Figure 2 Phylogenetic tree showing the relationship between the flaviviruses. The complete nucleotide sequence of every strain of JEV for which the complete sequence is available, plus representative strains of other important flaviviruses, were aligned using the Vector NTI sequence analysis program, and percentage differences calculated. The phylogenetic tree was then constructed using the maximum likelihood method (PAUP* version 4.04a; Sinauer Associates, Sutherlan, MA). The robustness of phylograms was evaluated by 1000 bootstrap replicates. Strain identities are given following the name of the virus, and GenBank accession numbers, or the relevant publications, are shown in parentheses. The tree was outgrouped using cell fusing agent (CFA). Horizontal branch lengths are proportional to the number of changes. POW = Powassan virus; $\mathrm{LGT}=$ Langat virus; $\mathrm{LI}=$ louping ill virus; $\mathrm{TBE}=$ tick-borne encephalitis virus; YF $=$ yellow fever virus; Den = dengue virus; $\mathrm{SLE}=\mathrm{St}$ Louis encephalitis virus; $\mathrm{WN}=$ West Nile virus; MVE $=$ Murray Valley encephalitis virus; JE = Japanese encephalitis virus. From Chiou and Chen, 2001; Jan et al, 1996. 
the cytoplasm of the infected cell (Chambers et al, 1990). This fusion, which occurs as the $\mathrm{pH}$ of the endosome drops, is thought to be mediated by a conformational change around a putative hinge region between domains I and II of the E protein, which brings a $\beta$ barrel-shaped fusion peptide at the tip of domain II to insert into the host cell membrane.

Recent cryoelectron microscopy studies of viruslike tick-borne encephalitis virus particles, and of dengue-2 virions, have helped further delineate the structure and organisation of the flavivirus fusion machinery. The structure of recombinant subviral particles (generated by coexpression of tick-borne encephalitis virus PrM and E proteins in mammalian cells) was determined to a resolution of $19 \AA$, and the atomic structure of the E protein, determined by x-ray crystallography, was fitted into it (Ferlenghi et al, 2001). The subviral particle (which is $30 \mathrm{~nm}$ across) contained 30 copies of the $\mathrm{E}$ dimer arranged in an icosohedral lattice with a triangulation number of 1 $(\mathrm{T}=1)$. By extrapolation to a whole flavivirus virion of $50 \mathrm{~nm}$, an arrangement of $90 \mathrm{E}$ dimers in a $\mathrm{T}=3$ lattice was predicted (Ferlenghi et al, 2001). And this is what has subsequently been shown for the whole dengue-2 virion. Kuhn and colleagues (2002) determined the structure of the dengue-2 virion with cryoelectron microscopy to $24 \AA$ resolution, and showed the virion has a well-organized outer protein shell, a lipid bilayer, and a less well defined inner nucleocapsid core (Figure 3a and b). Fitting the threedimensional (3D) structure of the flavivirus E protein showed that the icosohedral scaffold consists of $90 \mathrm{E}$ dimers, lying flat on the surface of the virion. The $\mathrm{M}$ protein was thought to be located in a gap between the E dimers (Figure 3c) (Kuhn et al, 2002). As the $\mathrm{pH}$-dependent conformational change in the
E proteins occurs, the E homodimers are thought to rearrange into homotrimers, thus exposing a patch of viral membrane for fusion (Kuhn et al, 2002). Recent crystallographic studies have shown the E1 protein of alphaviruses bears a striking similarity to the flavivirus $\mathrm{E}$ protein, including the arrangement of the three domains, and to the internal fusion peptide (Lescar et al, 2001). These flat fusion proteins of flaviviruses and alphaviruses have been designated class II fusion proteins, to distinguish them from the spikelike class I viral fusion proteins of orthomyxoviruses, paramyxoviruses, retroviruses, and filoviruses (Heinz and Allison, 2001). The flavivirus receptor has yet to be identified, but a highly sulphated heparan sulphate molecule may contribute to receptor binding (Chen et al, 1997; Su et al, 2001).

\section{Clinical epidemiology}

In northern temperate regions of Asia, JEV causes large summer epidemics, whereas in southern tropical regions, it causes endemic disease year round (Vaughn and Hoke, 1992). The occurrence of JEV genotypes I and III in northern regions and II and IV in southern regions led to the proposal that different genotypes may explain the differing clinical epidemiology (Chen et al, 1990, 1992). However, the recent arrival of a 'northern genotype I' isolate in Australia (Pyke et al, 2001), the observation that genotype III is associated with epidemic disease in northern Vietnam and endemic disease in southern Vietnam (Solomon et al, 2000a), and the idenitification of a putative $\mathrm{V}$ genotype (Uchil and Satchidanandam, 2001) suggest the current paradigm may need revising.

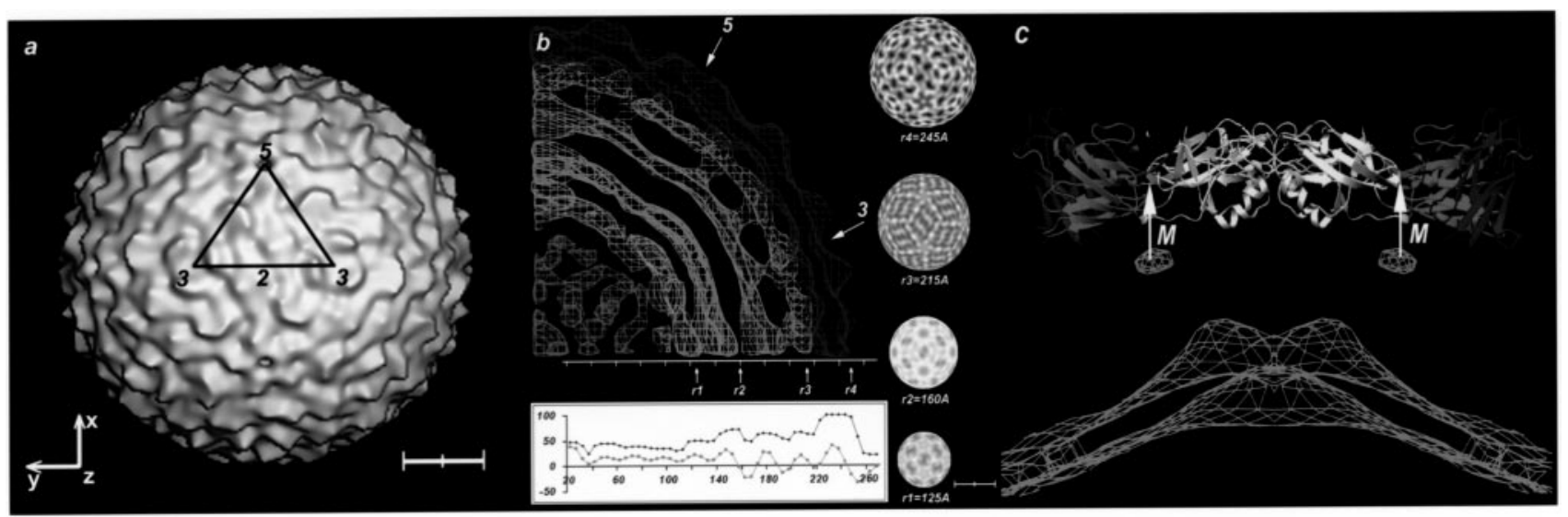

Figure 3 Cryo-electron microscopy of dengue-2 virus, from (Kuhn et al, 2002) with permission. (a) Surface shaded representation of the dengue-2 virion cryo-electron microscopy reconstruction at $24 \AA$ resolution, showing the outline of one icosohedral asymmetric unit. The scale bar represents $100 \AA$. (b) Cross section showing the cryoelectron microscopy density of the dengue-2 virion with a plot of the maximum (upper) and averaged (lower) density. Arrows indicate the position of the 5 -fold and 3-fold axes. To the side radial density sections at the defined radii, r1, r2, r3, r4 are shown. Higher density representing protein is shown in dark shading. The scale bar represents $175 \AA$ A. (c) Ribbon drawing of the E homodimer. Domains I, II, and III are shown along with the largest uninterrupted electron density peak outside the lipid bilayer (thought to represent the M protein). The white arrows indicate the position of the dimer holes. 
Because the rice paddy-breeding Culex mosquitoes, which transmit JEV, are unavoidable, the majority of the population in rural Asia has been infected with the virus by early adulthood. Humans become infected during the bite of an infected mosquito. Following inoculation, the virus is thought to replicate in the skin before being transported to local lymph nodes. Langerhans dendritic cells migrating from the skin to the lymph nodes have recently been implicated in this transport in experimental intradermal infection of BALB/C mice with West Nile virus (Johnston et al, 2000) and in volunteers receiving candidate live-attenuated dengue virus vaccines (Wu et al, 2000). Most JEV infections are asymptomatic, or cause a nonspecific febrile illness. In more severe cases, patients present with a meningoencephahlitis, though some present with aseptic meningitis, or a recently described polio-like acute flaccid paralysis (Figure 4) (Solomon et al, 1998), This later presentation also occurs in other flavivirus infections, including tick-borne encephalitis virus and West Nile virus (Asnis et al, 2000; Kaiser, 1995; Leis et al, 2002). Histopathological and imaging studies show viral infection and inflammation in the anterior horn cells of the spinal cord, providing an anatomical correlate for these presentations (Kumar et al, 1997; Miyake, 1964). In a similar way, recent radiological studies support earlier pathological studies implicating the basal ganglia, especially the substantia nigra and thalamus in the "parkinsonian" syndromes seen in JE, which include tremor, cogwheel rigidity, and masklike facies (Kumar et al, 1997; Misra and Kalita, 1997; Murgod et al, 2001). Other movement disorders and more severe dystonias may also occur (Kalita and Misra, 2000; Solomon and Vaughn, 2002). Seizures are common in JE (Kumar et al, 1990; Misra and Kalita, 2001), and it has recently been shown that multiple seizures and status epilepticus were associated with hypoxic brain metabolism, raised intracranial pressure, brainstem herniation syndromes, and a poor prognosis (Solomon et al, 2002a). In many patients, the clinical manifestations of status epilepticus were subtle (twitching of a digit, eyebrow, or lip), and could be missed easily, without electroencephalographic monitoring. Rigorous attention to these secondary complications of infection may improve the outcome.

\section{Pathogenesis}

In animal models, JEV strains differ in both their neuroinvasiveness (following peripheral inoculation) and neurovirulence (following intracranial inoculation). This may be a consequence of the high viremia achieved by some strains. In mice, JEV strains with higher neurovirulence produce higher viremias than those with lower neurovirlunce (Huang and Wong, 1963; Ni and Barrett, 1996). An analysis of the nucleotide and amino acid sequences showed changes

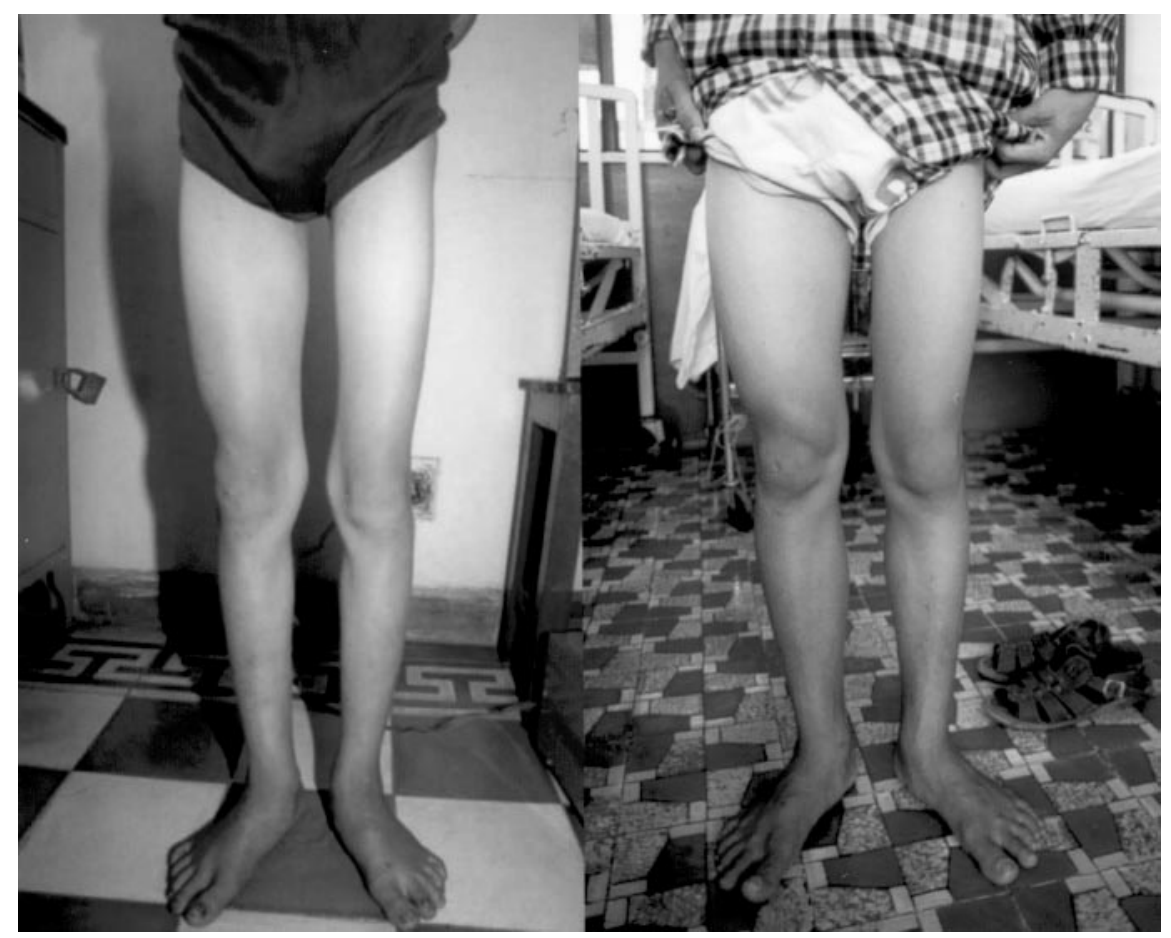

Figure 4 Poliomyelitis-like acute flaccid paralysis in Japanese encephalitis. These two Vietnamese children have a characteristic wasting and weakness of the left quadriceps 1 year after they initially presented with a rapid onset of asymmetrical flaccid paralysis. Reproduced with permission from Solomon et al, 1998, and Solomon, 2000. 
in the structural, nonstructural, and noncoding regions were associated with the neurovirulent strains. The E protein has been shown to have a major role in determination of virulence phenotype, and single amino acid substitutions are sufficient to cause loss of neurovirulence or neuroinvasiveness ( $\mathrm{Ni}$ et al, 1994, 1995). Two mechanisms mediated by E protein may be involved-attachment of the virus to the receptor and fusion of viral and host cell membranes. The putative receptor binding site of flaviviruses lies in an exposed hydrophilic region of domain III of the envelope protein, which in some mosquito-borne flaviviruses includes the integrinbinding motif arginine-glysine-aspartate (RGD). Substitutions around position E306 on the exposed lateral surface of domain III, at or close to this RGD motif, are associated with loss of neuroinvasiveness (Holzmann et al, 1990; Lee and Lobigs, 2000; Ni and Barrett, 1996). Another group of flavivirus variants with altered virulence has amino acid changes in the putative hinge region. For example, several studies of JEV and Murray Valley encephalitis virus neutralization escape variants with low neuroinvasiveness for mice have shown changes around positions 52 and 270-277 of the E protein, both of which lie in this hinge region (Cecilia and Gould, 1991; Hasegawa et al, 1992; McMinn et al, 1996). A substitution at E279 in a chimeric yellow fever/JEV (see below) was recently shown to affect neurovirulence for mice and monkeys (Monath et al, 2002a).

The pathogenesis of flavivirus encephalitis appears to be a combination of direct, virally mediated damage and the host inflammatory response. The host immune reponse comprises antibody-mediated immunity, particularly against the E and NS1 proteins, and cell-mediated immunity, including cytotoxic T lymphocytes (Johnson et al, 1985; Konishi et al, 1995). Recent attention has focused on the role of apoptosis in the pathogenesis of arboviral encephalitis. Apoptosis has been shown in vitro in a range of cell lines for different flaviviruses, including St Louis encephalitis virus, West Nile virus, Murray Valley encephalitis virus, and JEV (Jan et al, 2000; Liao et al, 1997; Parquet et al, 2002). It has also been shown in animal models of West Nile encephalitis and neurological dengue infection (Despres et al, 1998; Xiao et al, 2001). In vitro apoptosis was associated with a rise in the expression of nuclear factor kappa B (Liao et al, 2001), the proapoptotic bax gene (Parquet et al, 2002), and reactive oxygen intermediates (Raung et al, 2001) including nitric oxide production (Lin et al, 2002).

\section{Vaccine development}

Safe effective formalin-inactivated vaccines against JEV have been available for at least 30 years (Tsai, 2000). Vaccine produced in Japan from the prototype
Nakayama strain is available internationally under the Biken label, and a vaccine made from Beijing-1 strain is also used in Japan. Although used by travellers, and in rich Asian countries, the Biken vaccine's cost and complex production have meant it has not been used widely in many countries that need it. Moreover, although the risk of serious side effects is actually comparable to other vaccines (about one in one million doses), the vaccine has developed something of a bad reputation (Shlim and Solomon, 2002). These difficulties have stimulated efforts to develop improved vaccines. An inactivated tissue culture-derived vaccine, prepared from JEV P3 strain grown in primary hamster kidney cells, has been used in China since the late 1960s. In the last decade, vero cell-derived inactivated vaccines have also been developed, and are entering clinical trials.

However, live attenuated vaccines appear to offer the best promise for the future, because less virus is needed to produce a satisfactory immune response (making them cheaper to manufacture), and fewer doses are needed (making them easier to give). In the 1980s, the Chinese developed a live attenuated vaccine, named SA14-14-2, by empirically passaging JEV strain SA14 through primary hamster kidney cells (Xin et al, 1988). Six amino acid changes in the E protein, and three in the nonstructural genes, were associated with the attenuation (Ni et al, 1994). SA1414-2 has proved to be safe, efficacious, and cheap. In open-label studies in China involving more than 600,000 children, the vaccine was shown to have a low incidence of mild, nonspecific side effects (Ma et al, 1993). In a retrospective case-control study in which the prevalence of vaccination was compared in $56 \mathrm{JE}$ cases, and nearly 1300 age-matched controls, in affected villages, the vaccines efficacy was shown to be $80 \%$ for a single dose and $98 \%$ with two doses (Hennessy et al, 1996). More than 200 million doses of SA14-14-2 have been delivered in China since 1988, with very few reported side effects. However, regulatory approval for the vaccine's wider use outside of China has been delayed because of concerns about its production. In particular, primary hamster kidney cells have not been used previously for live vaccine production, and there are concerns that the materials used in the production of the original seed viruses may not have complied with international GMP ('good manufacturing practice'). However, given the number of doses administered already to Chinese children without apparent harm, and the current disease burden of JE across Asia, it might be argued that whilst waiting for the development of newer vaccines, the overall benefit of using the current vaccine would outweigh the perceived risk.

One new vaccine in development is a chimeric vaccine in which the PrM and E genes of attenuated JEV stain SA14-14-2 were inserted into an 


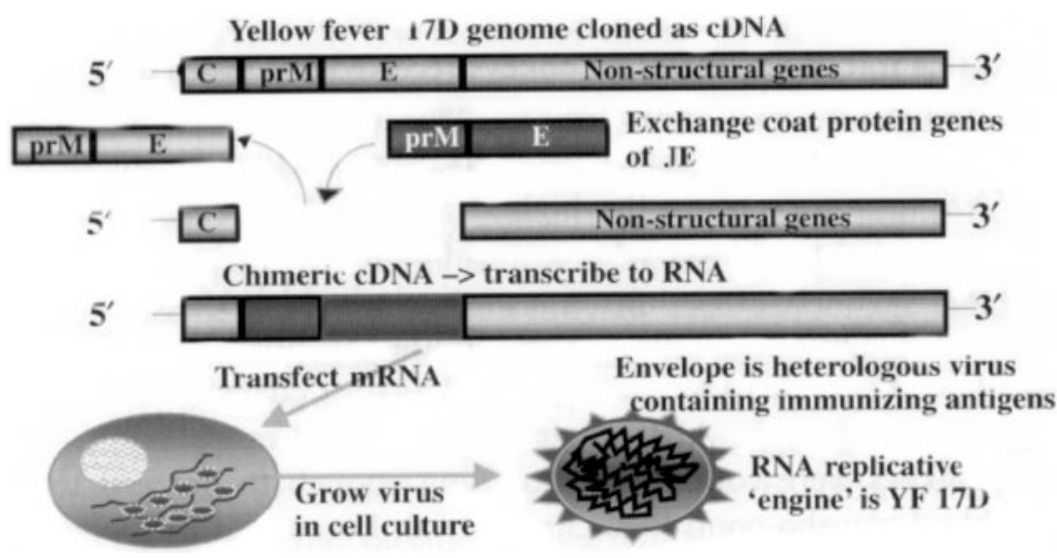

Figure 5 Schematic representation of the Chimeric yellow fever JE vaccine. The PrM and PrE genes of JE strain SA14-14-2 are inserted into the backbone of yellow fever vaccine strain 17D. From Monath, 2002, with permission.

infectious clone of the 17D yellow fever vaccine strain (Figure 5). The chimeric virus (ChimerivaxJE) replicated efficiently in vitro, and was shown to be safe in mice and nonhuman primates-being even more attenuated than the original 17D yellow fever strain (Monath et al, 2000). Attenuation of the chimeric virus was shown to depend on clusters of at least three of the six amino acid changes in the E protein (Arroyo et al, 2001). The vaccine has recently been given to 12 human volunteers in a phase I trial, and was shown to be safe and immunogenic (Monath et al, 2002b). A similar approach, using the same 17D yellow fever virus backbone, is being used to develop chimeric vaccines against West Nile and Dengue (Guirakhoo et al, 2002). An attenuated vaccinia virus strain has also been used as a vector to deliver JEV structural genes. Although high titres of neutralizing antibodies were elicited in monkeys, and vaccinia-naïve human volunteers, humans who had previously been vaccinated with vaccinia did not produce antibody against JEV (Kanesa-thasan et al, 2000), limiting the vaccines potential for future development. Alternative routes of vaccine administration are also being considered in preclinical studies: Ramakrishna and colleagues (1999) showed that oral immunization of mice with live JEV induced a brisk protective immune response against subsequent intracranial challenge.

\section{References}

Anderson JF, Rahal JJ (2002). Efficacy of interferon alpha$2 \mathrm{~b}$ and ribavirin against West Nile virus in vitro. Emerg Infect Dis 8: 107-108.

Arroyo J, Guirakhoo F, Fenner S, Zhang ZX, Monath TP, Chambers TJ (2001). Molecular basis for attenuation of neurovirulence of a yellow fever Virus/Japanese encephalitis virus chimera vaccine (ChimeriVax-JE). J Virol 75: 934-942.

Asnis DS, Conetta R, Teixeira AA, Waldman G, Sampson BA (2000). The West Nile virus outbreak of 1999 in

\section{Prospects for antiviral treatment}

There is no established antiviral treatment for JEV or any other flavivirus infection. A variety of compounds has shown antiviral activity in vitro and or animal models of infection (Leyssen et al, 2000). Recently, salicylates and nonsteroidal antiinflammatory drugs were shown to suppress the in vitro replication of JEV, and prevent apoptosis of infected cells (Chen et al, 2002; Liao et al, 2001). This did not appear to be via suppression of nuclear factor kappa B activation, but may be via mitogen-activated kinase (Liao et al, 2001). Interferon alpha, a glycoprotein cytokine that is produced naturally in response to viral infections, including JEV (Burke and Morrill, 1987), has been the most promising antiviral candidate. In tissue culture, recombinant interferon is effective against JEV and other arboviruses including West Nile virus (Anderson and Rahal, 2002; Harinasuta et al, 1984). In the 1980s, it was given in open trials to a small number of Thai JE patients with encouraging results (Harinasuta et al, 1985). However, a recently completed double-blind placebo-controlled trial in Vietnamese children with JE (the first randomized controlled antiviral trial for any flavivirus) showed that although interferon alpha may have delayed the time to death, it made no impact on the overall outcome (Solomon et al, 2002b).

New York: the Flushing Hospital experience. Clin Infect Dis 30: 413-418.

Burke DS, Morrill JC (1987). Levels of interferon in the plasma and cerebrospinal fluid of patients with acute Japanese encephalitis. J Infect Dis 155: 797799.

Cecilia D, Gould EA (1991). Nucleotide changes respsonsible for loss of neuroinvasiveness in Japanese encephalitis virus neutralisation-resistant mice. Virology 181: 70-77. 
Chambers TJ, Hahn CS, Galler R, Rice CM (1990). Flavivirus genome organisation, expression and replication. Annu Rev Microbiol 44: 649-688.

Chen CJ, Raung SL, Kuo MD, Wang YM (2002). Suppression of Japanese encephalitis virus infection by non-steroidal anti-inflammatory drugs. J Gen Virol 83: 1897-1905.

Chen WR, Ricco-Hesse R, Tesh RB (1992). A new genotype of Japanese virus from Indonesia. Am J Trop Med Hyg 47: 61-69.

Chen WR, Tesh RB, Ricco-Hesse R (1990). Genetic variation of Japanese encephalitis virus in nature. J Gen Virol 71: 2915-2922.

Chen Y, Maguire T, Hileman RE, Fromm JR, Esko JD, Linhardt RJ, Marks RM (1997). Dengue virus infectivity depends on envelope protein binding to target cell heparan sulphate. Nat Med 3: 866-871.

Chiou SS, Chen WJ (2001). Mutations in the NS3 gene and $3^{\prime}$-NCR of Japanese encephalitis virus isolated from an unconventional ecosystem and implications for natural attenuation of the virus. Virology 289: 129-136.

Despres P, Frenkiel MP, Ceccaldi PE, Duarte Dos Santos C, Deubel V (1998). Apoptosis in the mouse central nervous system in response to infection with mouseneurovirulent dengue viruses. J Virol 72: 823-829.

Ferlenghi I, Clarke M, Ruttan T, Allison SL, Schalich J, Heinz FX, Harrison SC, Rey FA, Fuller SD (2001). Molecular organization of a recombinant subviral particle from tick-borne encephalitis virus. Mol Cell 7: 593-602.

Guirakhoo F, Pugachev K, Arroyo J, Miller C, Zhang ZX, Weltzin R, Georgakopoulos K, Catalan J, Ocran S, Draper $\mathrm{K}$, Monath TP (2002). Viremia and immunogenicity in nonhuman primates of a tetravalent yellow fever-dengue chimeric vaccine: genetic reconstructions, dose adjustment, and antibody responses against wild-type dengue virus isolates. Virology 298: 146-159.

Harinasuta C, Nimmanitya S, Titsyakorn U (1985). The effect of interferon alpha on two cases of Japanese encephalitis in Thailand. Southeast Asian J Trop Med Pub Health 16: 332-336.

Harinasuta C, Wasi C, Vithanomsat S (1984). The effect of interferon on Japanese encephalitis virus in vitro. Southeast Asian J Trop Med Pub Health 15: 564-568.

Hasegawa H, Yoshida M, Shiosaka T, Fujita S, Kobayashi $Y$ (1992). Mutations in the envelope protein of Japanese encephalitis virus affect entry into cultured cells and virulence in mice. Virology 191: 158-165.

Heinz FX, Allison SL (2001). The machinery for flavivirus fusion with host cell membranes. Curr Opin Microbiol 4: 450-455.

Hennessy S, Zhengle L, Tsai TF, Strom BL, Chao-Min W, Hui-Lian L, Tai-Xiang W, Hong-Ji Y, Qi-Mau L, Karabatsos N, Bilker WB, Halstead SB (1996). Effectiveness of live-attenuated Japanese encephalitis vaccine (SA14-14-2): a case control study. Lancet 347: 15831586.

Holzmann H, Heinz FX, Mandl C, Guirakhoo F, Kunz C (1990). A single amino acid substitution in envelope protein of tick borne encephalitis virus leads to attenuation in the mouse model. J Gen Virol 64: 5156-5159.

Huang CH, Wong C (1963). Relation of the peripheral multiplication of Japanese B encephalitis virus to the pathogenesis of the infection in mice. Acta Virol 7: 322-330.

Jan JT, Chen BH, Ma SH, Liu CI, Tsai HP, Wu HC, Jiang SY, Yang KD, Shaio MF (2000). Potential dengue virustriggered apoptotic pathway in human neuroblastoma cells: arachidonic acid, superoxide anion, and NFkappaB are sequentially involved. J Virol 74: 8680-8691. Jan LR, Chen KL, Lu CF, Wu YC, Horng CB (1996). Complete nucleotide sequence of the genome of Japanese encephalitis virus ling strain: the presence of a 25nucleotide deletion in the $3^{\prime}$-nontranslated region. Am J Trop Med Hyg 55: 603-609.

Johnson RT, Burke DS, Elwell M, Leake CJ, A N, Hoke CH, Lorsomrudee W (1985). Japanese encephalitis: immunocytochemical studies of viral antigen and inflammatory cells in fatal cases. Ann Neurol 18: 567-573.

Johnston LJ, Halliday GM, King NJ (2000). Langerhans cells migrate to local lymph nodes following cutaneous infection with an arbovirus. J Invest Dermatol 114: 560-568.

Kaiser R (1995). Tick-borne encephalitis in southern Germany. Lancet 345: 463.

Kalita J, Misra UK (2000). Markedly severe dystonia in Japanese encephalitis. Mov Disord 15: 1168-1172.

Kanesa-thasan N, Smucny JJ, Hoke CH, Marks DH, Konishi E, Kurane I, Tang DB, Vaughn DW, Mason PW, Shope RE (2000). Safety and immunogenicity of NYVAC-JEV and ALVAC-JEV attenuated recombinant Japanese encephalitis virus-poxvirus vaccines in vaccinia-nonimmune and vaccinia-immune humans. Vaccine 19: 483-491.

Konishi E, Mason PW, Innis BI, Ennis FA (1995). Japanese encephalitis virus-specific proliferative responses of human peripheral blood T lymphocytes. Am J Trop Med Hyg 53: 278-283.

Kuhn RJ, Zhang W, Rossmann MG, Pletnev SV, Corver J, Lenches E, Jones CT, Mukhopadhyay S, Chipman PR, Strauss EG, Baker TS, Strauss JH (2002). Structure of dengue virus: implications for flavivirus organization, maturation, and fusion. Cell 108: 717-725.

Kumar S, Misra UK, Kalita J, Sawani V, Gupta RK, Gujral R (1997). MRI in Japanese encephalitis. Am J Med Sci 39: 180-184.

Kumar R, Mathur A, Kumar A, Sharma S, Chakraborty S, Chaturvedi UC (1990). Clinical features and prognostic indicators of Japanese encephalitis in children in Lucknow (India). Indian J Med Res 91: 321-327.

Lee E, Lobigs $M$ (2000). Substitutions at the putative receptor-binding site of an encephalitic flavivirus alter virulence and host cell tropism and reveal a role for glycosaminoglycans in entry. $J$ Virol 74: 8867-8875.

Leis AA, Stokic DS, Polk JL, Dostrow V, Winkelmann M (2002). A Poliomyelitis-like syndrome from West Nile virus infection. N Engl J Med 347: 1279-1280.

Lescar J, Roussel A, Wien MW, Navaza J, Fuller SD, Wengler G, Rey FA (2001). The Fusion glycoprotein shell of Semliki Forest virus: an icosahedral assembly primed for fusogenic activation at endosomal pH. Cell 105: 137148.

Leyssen P, De Clercq E, Neyts J (2000). Perspectives for the treatment of infections with Flaviviridae. Clin Microbiol Rev 13: 67-82.

Liao CL, Lin YL, Wang JJ, Huang YL, Yeh CT, Ma SH, Chen LK (1997). Effect of enforced expression of human bcl-2 on Japanese encephalitis virus induced apoptosis in cultured cells. J Virol 71: 5963-5971.

Liao CL, Lin YL, Wu BC, Tsao CH, Wang MC, Liu CI, Huang YL, Chen JH, Wang JP, Chen LK (2001). Salicylates inhibit flavivirus replication independently of blocking nuclear factor kappa B activation. J Virol 75: 78287839 . 
Lin CF, Lei HY, Shiau AL, Liu HS, Yeh TM, Chen SH, Liu CC, Chiu SC, Lin YS (2002). Endothelial cell apoptosis induced by antibodies against dengue virus nonstructural protein 1 via production of nitric oxide. J Immunol 169: $657-664$.

Ma X, Yu YX, Wang SG (1993). Observations on safety and serological efficacy from a large scale field trial of Japanese encephalitis vaccine. Chin J Biol 6: 188191.

McMinn PC, Dalgarno L, Weir RC (1996). A comparison of the spread of Murray Valley encephalitis viruses of high or low neuroinvasiveness in the tissues of Swiss mice after peripheral inoculation. Virology 220: 414423.

Misra UK, Kalita J (1997). Movement disorders in Japanese encephalitis. J Neurol 244: 299-303.

Misra UK, Kalita J (2001). Seizures in Japanese encephalitis. J Neurol Sci 190: 57-60.

Miyake M (1964). The pathology of Japanese encephalitis. WHO Bull 30: 153-160.

Monath TP (2002). Japanese encephalitis vaccines: current vaccines and future prospects. Curr Top Microbiol Immunol 267: 105-138.

Monath TP, Arroyo J, Levenbook I, Zhang ZX, Catalan J, Draper K, Guirakhoo F (2002a). Single mutation in the flavivirus envelope protein hinge region increases neurovirulence for mice and monkeys but decreases viscerotropism for monkeys: relevance to development and safety testing of live, attenuated vaccines. J Virol 76: 1932-1943.

Monath TP, Levenbook I, Soike K, Zhang ZX, Ratterree M, Draper K, Barrett AD, Nichols R, Weltzin R, Arroyo J, Guirakhoo F (2000). Chimeric yellow fever virus 17DJapanese encephalitis virus vaccine: dose-response effectiveness and extended safety testing in rhesus monkeys. J Virol 74: 1742-1751.

Monath TP, McCarthy K, Bedford P, Johnson CT, Nichols R, Yoksan S, Marchesani R, Knauber M, Wells KH, Arroyo J, Guirakhoo F (2002b). Clinical proof of principle for ChimeriVax: recombinant live, attenuated vaccines against flavivirus infections. Vaccine 20: 10041018.

Murgod UA, Muthane UB, Ravi V, Radhesh S, Desai A (2001). Persistent movement disorders following Japanese encephalitis. Neurology 57: 2313-2315.

Ni H, Barrett ADT (1996). Molecular differences between wild-type Japanese encephalitis virus strains of high and low mouse neuroinvasiveness. J Gen Virol 77: 14491455.

Ni H, Burns NJ, Chang GJ, Zhang MJ, Wills MR, Trent DW, Sanders PG, Barrett AD (1994). Comparison of nucleotide and deduced amino acid sequence of the $5^{\prime}$ non-coding region and structural protein genes of the wild-type Japanese encephalitis virus strain SA14 and its attenuated vaccine derivatives. J Gen Virol 75: 15051510.

Ni H, Chang GJ, Xie H, Trent DW, Barrett AD (1995). Molecular basis of attenuation of neurovirulence of wild-type Japanese encephalitis virus strain SA14. J Gen Virol 76 ( Pt 2): 409-413.

Parquet MC, Kumatori A, Hasebe F, Mathenge EG, Morita K (2002). St. Louis encephalitis virus induced pathology in cultured cells. Arch Virol 147: 1105-1119.

Pyke AT, Williams DT, Nisbet DJ, van den Hurk AF, Taylor CT, Johansen CA, Macdonald J, Hall RA, Simmons RJ,
Mason RJ, Lee JM, Ritchie SA, Smith GA, Mackenzie JS (2001). The appearance of a second genotype of Japanese encephalitis virus in the Australasian region. Am J Trop Med Hyg 65: 747-753.

Ramakrishna C, Desai A, Shankar SK, Chandramuki A, Ravi V (1999). Oral immunisation of mice with live Japanese encephalitis virus induces a protective immune response. Vaccine 17: 3102-3108.

Raung SL, Kuo MD, Wang YM, Chen CJ (2001). Role of reactive oxygen intermediates in Japanese encephalitis virus infection in murine neuroblastoma cells. Neurosci Lett 315: 9-12.

Rey FA, Heinz FX, Mandl C, Kunz C, Harrison C (1995). The envelope glycoprotein from tick-borne encephalitis virus at 2 A resolution. Nature 375: 291-298.

Roehrig JT, Hunt AR, Johnson AJ, Hawkes RA (1989). Synthetic peptides derived from the deduced amino acid sequence of the E-glycoprotein of Murray Valley encephalitis virus elicit antiviral antibody. Virology 171: 49-60.

Shlim DR, Solomon T (2002). Japanese encephalitis vaccine for travelers: exploring the limits of risk. Clin Infect Dis 35: 183-188.

Solomon T (2000). Japanese encephalitis. In: Neurobase. Gilman S, Goldstein GW, Waxman SG, (eds). San Diego: Medlink Publishing. Available on CD-ROM.

Solomon T, Dung NM, Kneen R, Gainsborough M, Vaughn DW, Khanh VT (2000a). Japanese encephalitis. J Neurol Neurosurg Psychiatry 68: 405-415.

Solomon T, Dung NM, Kneen R, Thao LT, Gainsborough M, Nisalak A, Day NP, Kirkham FJ, Vaughn DW, Smith S, White NJ (2002a). Seizures and raised intracranial pressure in Vietnamese patients with Japanese encephalitis. Brain 125: 1084-1093.

Solomon T, Dung NM, Vaughn DW, Kneen R, Thao LTT, Raengsakulrach B, Day NPJ, Farrar J, Myint KSA, Nisalak A, White NJ (2000b). Neurological manifestations of dengue infection. Lancet 355: 1053-1059.

Solomon T, Dung NM, Wills B, Kneen R, Gainsborough M, Diet TV, Thuy TTN, Loan HT, Khanh VC, Vaughn DW, White NJ, Farrar JJ (2002b). A double-blind placebocontrolled trial of interferon alpha in Japanese encephalitis. Lancet 361: 821-826.

Solomon T, Kneen R, Dung NM, Khanh VC, Thuy TTN, Ha DQ, Day NPJ, Nisalak A, Vaughn DW, White NJ (1998). Poliomyelitis-like illness due to Japanese encephalitis virus. Lancet 351: 1094-1097.

Solomon T, Vaughn DW (2002). Clinical features and pathophysiology of Japanese encephalitis and West Nile virus infections. In: Current topics in microbiology and immunology: Japanese encephalitis and West Nile virus infections. Mackenzie JS, Barrett AD, Deubel V (eds). Berlin: Springer-Verlag, pp 171-194.

Stadler K, Allison SL, Schalich J, Heinz FX (1997). Proteolytic activation of tick-borne encephalitis virus by furin. J Virol 71: 8475-8481.

Su CM, Liao CL, Lee YL, Lin YL (2001). Highly sulfated forms of heparin sulfate are involved in japanese encephalitis virus infection. Virology 286: 206-215.

Tsai TF (2000). New initiatives for the control of Japanese encephalitis by vaccination: minutes of a WHO/CVI meeting, Bangkok, Thailand, 13-15 October 1998. Vaccine 18 (Suppl 2): 1-25.

Uchil PD, Satchidanandam V (2001). Phylogenetic analysis of Japanese encephalitis virus: envelope gene based 
analysis reveals a fifth genotype, geographic clustering, and multiple introductions of the virus into the Indian subcontinent. Am J Trop Med Hyg 65: 242-251.

Vaughn DW, Hoke CH (1992). The epidemiology of Japanese encephalitis: prospects for prevention. Epidemiol Rev 14: 197-221.

Wu SJ, Grouard-Vogel G, Sun W, Mascola JR, Brachtel E, Putvatana R, Louder MK, Filgueira L, Marovich MA, Wong HK, Blauvelt A, Murphy GS, Robb ML, Innes BL, Birx DL, Hayes CG, Frankel SS (2000). Human skin
Langerhans cells are targets of dengue virus infection. Nat Med 6: 816-820.

Xiao SY, Zhang H, Guzman H, Tesh RB (2001). Experimental yellow fever virus infection in the Golden hamster (Mesocricetus auratus). II. Pathology. J Infect Dis 183: 1437-1444.

Xin YY, Ming ZG, Peng GY, Jian A, Min LH (1988). Safety of a live-attenuated Japanese encephalitis virus vaccine (SA14-14-2) for children. Am J Trop Med Hyg 39: 214217. 